\title{
Kernos
}

Revue internationale et pluridisciplinaire de religion grecque antique

$13 \mid 2000$

Varia

\section{Maria Lucia SANCASSANO, Il serpente e le sue immagini. Il motivo del serpente nella poesia greca dall'Iliade all'Orestea}

\section{Pierre Somville}

\section{(2) OpenEdition \\ Journals}

Édition électronique

URL : http://journals.openedition.org/kernos/1330

DOI : 10.4000/kernos. 1330

ISSN : 2034-7871

\section{Éditeur}

Centre international d'étude de la religion grecque antique

\section{Édition imprimée}

Date de publication : 1 janvier 2000

ISSN : 0776-3824

\section{Référence électronique}

Pierre Somville, "Maria Lucia sancassano, II serpente e le sue immagini. II motivo del serpente nella poesia greca dall'lliade all'Orestea », Kernos [En ligne], 13 | 2000, mis en ligne le 16 juin 2011, consulté le 24 septembre 2020. URL : http://journals.openedition.org/kernos/1330 ; DOI : https://doi.org/ $10.4000 /$ kernos. 1330 
barbarie originelle, et plus particulièrement du cannibalisme, est aussi abordé quand l'A. montre que si celui-ci est généralement attribué par les Grecs à l'Autre, on le trouve aussi en Grèce : en Arcadie - pays qui passait pour attardé et à Mycènes, berceau même de la civilisation grecque.

Ouvrage exemplaire sur le plan de la méthode puisqu'il se trouve au point de convergence du comparatisme, de l'anthropologie et de la philologie, Mythes grecs convie à une réflexion sur la notion d'altérité dans l'antiquité et dans le monde moderne. Livre riche d'observations subtiles, il se révèle une mine d'informations érudites. Un index explicatif des noms de personnages permet utilement de faire le point dans un ouvrage qui brasse une matière dense et variée, ouvrant sur de très vastes horizons, tandis qu'une bibliographie mise à jour le complète utilement.

Isabelle Tassignon (Université de Liège)

Maria Lucia SANCASSANo, Il serpente e le sue immagini. Il motivo del serpente nella poesia greca dall Tliade all'Orestea, Como, Edizioni New Press, 1997. 1 vol. $17 \times 24 \mathrm{~cm}, 205$ p. (Biblioteca di Athenaeum, 36)

Ce texte d'une dissertation doctorale soutenue à l'Université de Marbourg en 1994 est le résultat d'une recherche philologique impeccablement menée, d'Homère à Eschyle en passant par la Théogonie d'Hésiode et les Lyriques. C'est donc toute la littérature grecque archaïque qui se trouve mise en coupes selon le thème récurrent, analogique, métaphorique et symbolique du serpent.

Motif d'épisème apotropaïque sur les écus de certains combattants, le serpent joue également dans l'Iliade un rôle oraculaire non négligeable en conjonction avec l'aigle notamment (XII, 200 et $s q$.). On le trouve aussi, dès le récit du départ en Aulide et jusqu'aux prodromes de la chute de Troie, lié à des images d'anticipation, le plus souvent funestes. Toutefois, en certains contextes, la connotation d'une valorisation positive qui s'y associe n'échappe pas à la sagacité de l'analyste.

Pour Hésiode, les choses se présentent différemment : l'animal y est vu sous des formes diverses comme un monstre répulsif, issu des ténèbres et finalement rejeté aux confins du monde «rationnel ». L'influence du Proche-Orient est dûment mentionnée par l'A. en ce qui concerne cet aspect négatif et proprement tératologique. De Pindare à Théognis, la moıkı $\lambda l \alpha$ des valeurs symboliques du reptile semble exprimer au mieux sa nature bifide et ambivalente. Il peut être nourricier autant que redoutable (Pind, Ol., VI, 39-47; Théogn., 599-602). Quant à l'Orestie qui semble être le véritable point de départ de toute cette enquête, elle

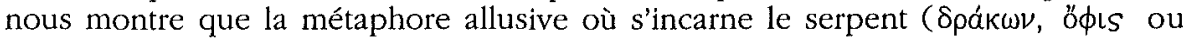
$\ddot{E} \chi\llcorner\delta \vee a)$ court tout au long du récit, dans les Choépbores surtout, ainsi qu'un fil de trame des plus évocateurs. De l'allusion initiale aux « petits de l'aigle » victimes du serpent jusqu'à l'apparition des Érinyes à un Oreste devenu lui-même

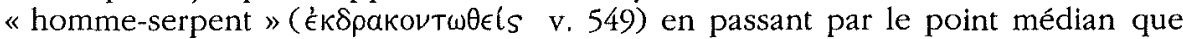
représente le fameux cauchemar de Clytemnestre (vv. 526-534), on assiste au rôle sémantiquement inducteur de cette métaphore eschyléenne, héritée d'un lointain passé et habilement réactivée en fonction des besoins de la progression dramatique. Rien d'essentiel n'échappe à l'œil de l'A., rien d'accidentel non plus, puis qu'elle a pris soin de débusquer son thème dans les ceuvres d'Eschyle précédant l'Orestie. Tout cet ensemble est bien convaincant. La perspective historico-religieuse y est toujours présente ainsi que toujours ouverte la perspective symbolique que requiert un pareil sujet. On peut seulement regretter qu'elle n'ait pas 
retenu dans son Corpus la «Suite pythique » de l'Hymne pseudo-homérique à Apollon.

Enfin, quelques broutilles d'usage : p. 13, 1. 1, il fallait écrire "au meilleur de son combat ... "; p. 194 et 195, " Areopago »; p. 199, "Wilamowitz-Moellendorff " et p. 203, ajouter entre Reichel et Rose une référence à la Psyche d'Erwin Rohde.

Pierre Somville

(Université de Liège)

Jean RudhardT, Thémis et les Hôrai. Recherche sur les divinités grecques de la justice et de la paix, Genève, Droz, 1999. 1 vol. $15 \times 22 \mathrm{~cm}, 167$ p. (Recherches et Rencontres. Publications de la Faculté des lettres de Genève, 14). ISBN : 2-600-00354-1.

Il faut saluer la publication du nouveau livre magistral de Jean Rudhardt. Ce volume, consacré à ce qu'on appelait auparavant des notions divinisées, met en évidence que Thémis, Eunomia, Dikè, et Eirènè ne sont pas des personnifications abstraites ou des allégories : l'auteur, se fiant à ce qu'exprime le langage mythique en insérant Thémis et les Hôrai dans une généalogie, et prenant acte de la constatation que ces entités recevaient un culte, montre que ce sont en fait de vraies divinités (qui ne sont pas le produit d'une invention tardive), et sonde le sentiment du divin qui se laisse déchiffrer à travers elles. C'est-à-dire que, dans la droite ligne d'une réflexion commencée depuis plusieurs décennies, il nous fait progresser dans la "compréhension » de la pensée religieuse grecque, dont le sens a longtemps échappé malgré les connaissances qu'on pouvait avoir à son sujet.

Dès son premier ouvrage - si bien nommé : Notions fondamentales de la pensée religieuse et actes constitutifs du culte, Genève, 1958 (réimprimé à Paris en 1992) -, Jean Rudhardt s'est imposé d'emblée comme l'un des spécialistes les plus perspicaces de la religion grecque. Suivant un système original, il s'attachait à appréhender les faits religieux tels qu'ils furent vécus à l'intérieur d'une société limitée dans l'espace et dans le temps, en essayant de rétablir en nous le contexte psychologique dans lequel venait s'inscrire la conduite d'un fidèle à l'occasion d'une circonstance concrète. C'est donc une méthode interne, qui vise à comprendre dans une même démarche, en une alliance significative, à la fois le culte et la pensée. La condition pour atteindre à pareille connivence intime entre le lecteur moderne et les textes anciens est de faire autant que possible table rase de nos modes de pensée, et en tout cas d'ordonner les faits hétérogènes rencontrés selon les catégories que la langue grecque nous propose. Aussi, dans la certitude que ces faits ne sauraient nous être exactement intelligibles hors de la langue employée par les hommes qui les ont vécus, l'A. part-il des textes pour y revenir sans cesse. Cette exigence de rigueur portée à un degré extrême dans des ouvrages dont le but immédiat n'est pas d'être une pure recherche sur le vocabulaire distingue les travaux de Jean Rudhardt de tous les autres, et fait de leur auteur un maître incontesté en matière de religion grecque. Les analyses lexicologiques et la lecture attentive des textes qui formaient déjà le socle de son premier livre ont constitué la base de tous les suivants jusqu'à celui-ci. C'est ainsi que la carrière de Jean Rudhardt n'a été jalonnée que d'ouvrages fondamentaux. Après la pensée religieuse et les actes du culte, la même méthode a en effet été appliquée par l'A. aux mythes (principalement cosmogoniques), en particulier dans deux livres ( $L e$ thème de l'eau primordiale dans la mytbologie grecque, Berne, 1971; Le rôle d'Éros et d'Aphrodite dans les cosmogonies grecques, Paris, 1986), ainsi que dans de nombreux articles, dont quelques-uns des plus anciens ont été réunis en 1981 